\title{
The effects and safety of intravitreal triamcinolone injections in the treatment of diabetic macular edema
}

\author{
Hanna M. Zając-Pytrus ${ }^{A-D}$, Radosław Kaczmarek ${ }^{C}$, Dorota Strońska-Lipowicz ${ }^{B}$, Maria Pomorska ${ }^{B}$, Marta Misiuk-Hojło \\ Department of Ophthalmology, Wroclaw Medical University, Poland \\ A - research concept and design; $\mathrm{B}$ - collection and/or assembly of data; $\mathrm{C}$ - data analysis and interpretation; \\ $D$ - writing the article; $E$ - critical revision of the article; $F$ - final approval of article
}

\section{Address for correspondence \\ Hanna Zając-Pytrus}

E-mail: hzp@spektrum.wroc.pl

\section{Funding sources}

none declared

\section{Conflict of interest}

none declared

Received on May 27, 2014

Revised on June 23, 2014

Accepted on September 16, 2014

\begin{abstract}
Background. Diabetic macular edema (DME) is responsible for three-quarters of vision-loss cases in diabetic eye disease. In most cases, early treatment by laser photocoagulation can only stabilize vision. Glucocorticoids have been used as a local pharmacological treatment in DME when the inflammation seems to have a pathological background.

Objectives. The aim of the study was to establish the effectiveness and safety of intravitreal triamcinolone injections in the treatment of DME.

Material and methods. Twenty mg intravitreal injections of triamcinole acetonide (IVTA) were applied to 110 DME patients after ineffective laserphotocoagulation or as an initial treatment. Best corrected visual acuity (BCVA) for distant and near vision, central retinal thickness and intraocular pressure (IOP) were analyzed before and after the treatment at intervals of 1 week, 1 month, 3 months and 6 months. The measurements were continued in cases of repeated IVTA.
\end{abstract}

Results. Statistically significant improvements were observed in BCVA in near and distant vision, as well as a decrease in central retinal thickness after all time-intervals following IVTA. BCVA in distant vision was not significantly improved after repeated IVTA. IOP increases were observed 1 week, 1 and 3 months after IVTA, but not at 6 months after IVTA. No sight-threatening side effects of IVTA were observed.

Conclusions. IVTA is useful in stabilizing DME progression, although its therapeutic effect may be timelimited.

Key words: diabetes, macular edema, triamcinolone

DOI

$10.17219 /$ acem/29849

Copyright

Copyright by Author(s)

This is an article distributed under the terms of the

Creative Commons Attribution Non-Commercial License

(http://creativecommons.org/licenses/by-nc-nd/4.0/) 
Diabetic macular edema (DME) caused by microvascular damage of the retinal center is responsible for threequarters of vision-loss cases in diabetic eye disease. ${ }^{1}$ Due to the increasing incidence of type II diabetes in the working-age population, DME has become a major public health problem. ${ }^{2}$ The Wisconsin Epidemiologic Study of Diabetic Retinopathy (WESDR) has shown that reduced central vision decreases the quality of life. ${ }^{3}$ The current common standard of DME treatment still relies on focal laser coagulation of leakage in defined retinal areas according to guidelines set out by the Early Treatment Diabetic Retinopathy Study (ETDRS). ${ }^{4}$ In most cases, early treatment by laser photocoagulation can only stabilize vision. According to the ETDRS study, 15\% of the treated patients, and as many as $25 \%$ with diffused edema, showed decreased visual acuity (a loss of $\geq 15$ ETDRS letters) after a 3-year follow-up interval. ${ }^{4}$ Grid laser treatment covering the whole macular region with a grid of laser spots is mostly ineffective in diffuse DME. Therefore therapeutic strategies involve combating systemic risk factors (intensive glycemic and blood pressure control), using pharmacological therapies and even surgical treatment in refractory cases.

Due to their anti-inflammatory effect, glucocorticoids have been used as a local pharmacological treatment in DME when the inflammation seems to have a pathological background. Intravitreal triamcinolone injections of different doses $(1,4,8,12,16$ and $20 \mathrm{mg})$ have been found effective in reducing macular edema and improving vision in refractory DME following laser treatment, or even as an initial treatment. ${ }^{5-8}$ The bigger the dose of triamcinolone given intravitreally the longer the drug remains active, which means that larger doses can reduce the risk of endophthalmitis, as fewer injections are subsequently required. ${ }^{9}$

Steroid-related adverse events, e.g. cataract and elevated intraocular pressure (IOP), should be weighed against the benefits of the treatment. ${ }^{10,11}$

The aim of this prospective study was to report anatomic changes and best corrected visual acuity (BCVA) for distant and near vision in response to intravitreal $20 \mathrm{mg}$ triamcinolone acetonide injections in patients with DME. Side effects of the intraocular steroid - cataract progression and increases in IOP - were also analyzed.

\section{Material and methods}

This prospective interventional study was conducted on a series of eyes with DME that had not been responsive to laserphotocoagulation, and eyes with DME being treated for the first time with intravitreal triamcinolone acetonide injections between December 2006 and December 2009 (Table 1). The Wroclaw Medical University Ethics Committee approved the study protocol. All the patients were informed of all possible side effects of the proposed treatment and consented to the therapy.

Each patient underwent BCVA measurements based on ETDRS charts for distant vision and on Radner charts for near vision. Each patient was examined using slit-lamp biomicroscopy, which included Goldmann tonometry IOP measurement, gonioscopy and fundus ophthalmoscopy. The retinal thickness of the central $1 \mathrm{~mm}$ part of the retina was obtained using optical coherence tomography (OCT) mapping software (Stratus OCT III, Carl Zeiss, Dublin, USA). The eye was prepared using Oftaquix drops (Santen Oy, Tampere, Finland) 4 times a day for 3 days before the procedure, and was treated in a standard preoperative fashion with alcaine drops for local anesthesia and $5 \%$ povidone/iodine. An eyelid speculum was used to stabilize the eyelids, and an injection of $20 \mathrm{mg}(0.1 \mathrm{~mL})$ of triamcinolone acetonide was performed with a 30-gauge needle $3.5-4.0 \mathrm{~mm}$ posterior to the limbus, through the inferotemporal pars plana.

Two different pharmaceutical triamcinolone acetonide products were used, depending on availability: preservative-free Aurocort (Aurolab, Veerapanjan, India), intended for intravitreal use; or Kenalog (Bristol-Myers Squibb, Anagni, Italy), used off label. In both cases, the drug volume was minimized by eliminating the solvent after dividing the ampule in half and centrifuging the drug.

After the injection, the IOP was checked and paracentesis was performed if needed. The patients were instructed to administer Oftaquix for the next three days. The patients were examined the day after the injection, 1 week later, and 1, 3 and 6 months after the initial injection. Reinjections were performed in cases of recurrent edema. Reevaluations were carried out at the same time intervals.

In cases complicated by the development of cataracts, phacoemulsification with intraocular artificial lens implantation was carried out with an intravireal triamcinolone acetonide injection if recurrent DME was also present. Recurrence was defined as a decrease in BCVA along with an increase in intraretinal fluid due to macular

Table 1. The study group with DME

\begin{tabular}{|l|c|c|c|c|c|} 
Sex & Patients & Type I diabetes & Type II diabetes & Age & $\begin{array}{c}\text { Duration of diabetes } \\
\text { (years) }\end{array}$ \\
\hline Women & $58(62)$ & 6 & 52 & $63.7 \pm 10.8$ & \\
Men & $52(51)$ & 3 & 49 & $63.2 \pm 9.0$ & $1-39$ years \\
\hline Totally & $110(113)$ & 9 & 101 & $63.5 \pm 10$ & 10 \\
\hline
\end{tabular}


edema on OCT, following partial or complete resolution in previous follow-up visits. The main assessments for the study included changes in distant and near BCVA, OCT measurements of central retinal thickness and IOP. Interval data were analyzed during follow-ups 1 week, 1 month, 3 months and 6 months after the procedure.

\section{Statistical analysis}

The results were statistically verified using Epi Info v. 3.4.3. software (Centers for Disease Control and Prevention, Atlanta, USA). Mean values and standard deviations were calculated for normally distributed variables (parametric tests). Median tests were used for other variables (non-parametric tests). The $\chi^{2}$ test was used to compare categorical values and Student's t-test or the Mann-Whitney U test were used to compare numerical variables. Student's t-test was used to compare the mean values of the examined parameters, and the Wilcoxon test was used for the medians. A p value of less than 0.05 was considered statistically significant.

\section{Results}

BCVA for distance was found to be significantly better 1 week, 1 month, 3 and 6 months after the first IVTA injection in comparison to the initial BCVA (Fig. 1). After repeated (2 and 3) IVTA injections, no significant improvement in distant BCVA was observed at any of the follow-up intervals. Therefore the difference between the initial and final distant BCVA among the patients who received repeated injections was not statistically significant. BCVA for reading was significantly better at all of the follow-up time points after the first injection (Fig. 2). After each of the repeated IVTA injections, the difference between the initial and observed BCVA for reading was

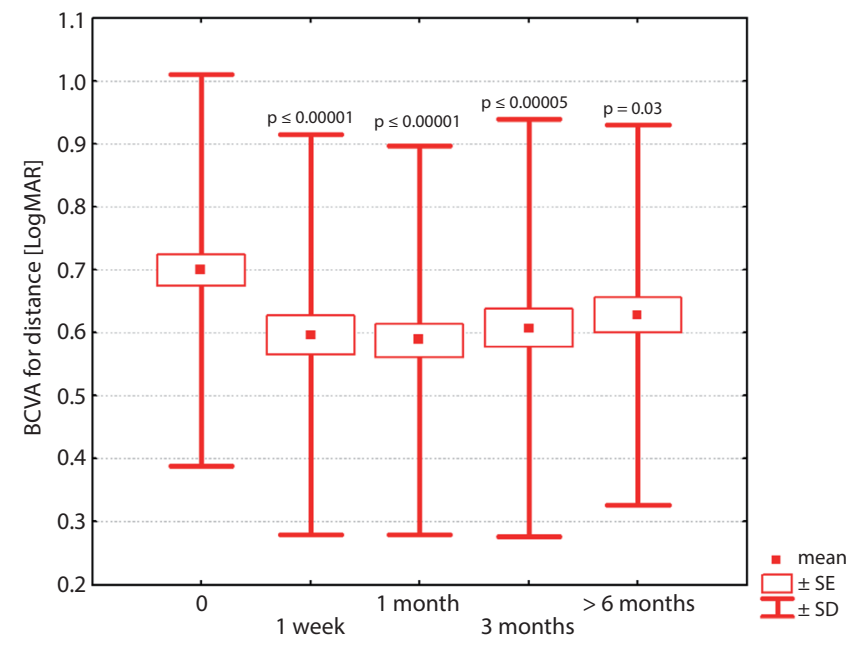

Fig. 1. Best corrected visual acuity (BCVA) for distance vision on the LogMar scale in the follow-ups in comparison to the initial distance BCVA. SE - standard error; SD - standard deviation

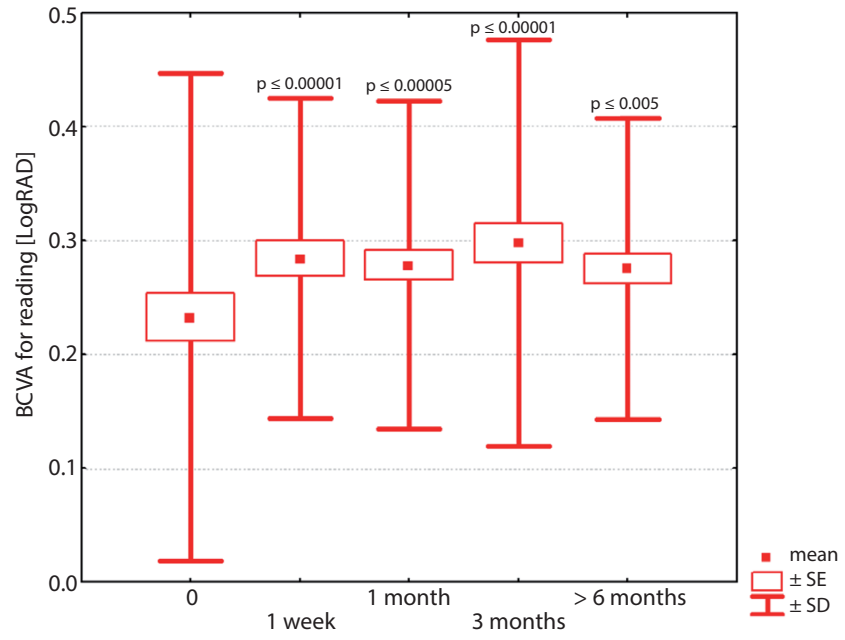

Fig. 2. Best corrected visual acuity (BCVA) for reading on the LogMar scale in the follow-ups in comparison to the initial reading BCVA. SE - standard error; SD - standard deviation

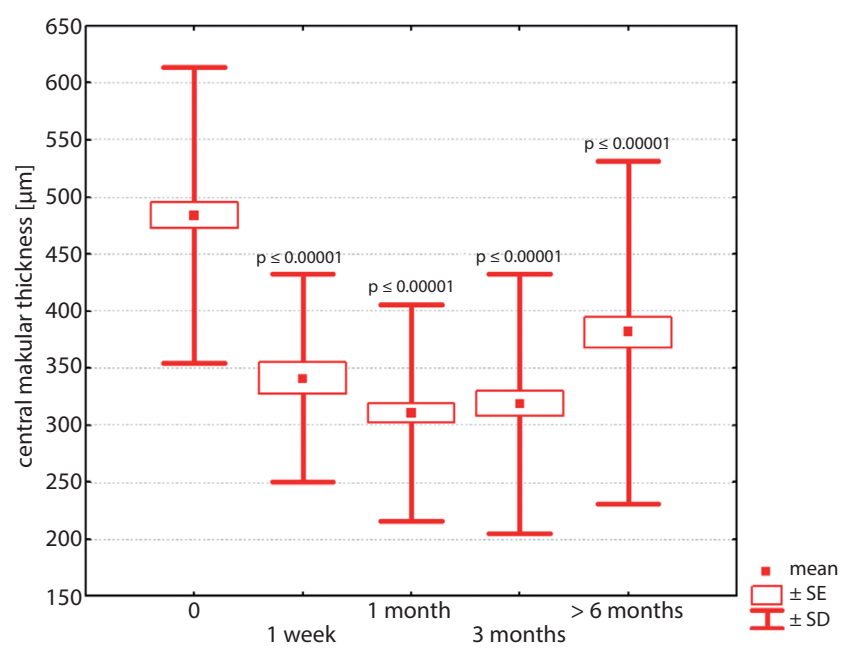

Fig. 3. Central macular thickness $(\mu \mathrm{m})$ in the follow-ups in comparison to the initial central macular thickness $(\mu \mathrm{m})$. SE - standard error; SD - standard deviation

significantly better, with the exception of the measurements 1 month and 6 months after the third additional injection. The final difference between the initial and improved BCVA for reading over the whole investigated period was statistically significant $(\mathrm{p}<0.05)$.

In the study group, a decrease was observed in central retinal thickness, which was statistically significant in comparison to the initial value at all of the follow-up time points after the first injection (Fig. 3).

Significant improvements were observed in the OCT measurements after all of the repeated injections, with the exception of the 6-month follow-up after the third injection in 13 patients.

Increases in IOP values were noted at the 1-week, 1-month and 3-month follow-up periods in comparison to the initial measurements. The difference in IOP was no longer statistically significant 6 months after the first injection ( $p=0.279$, Fig. 4 ). The difference between the 


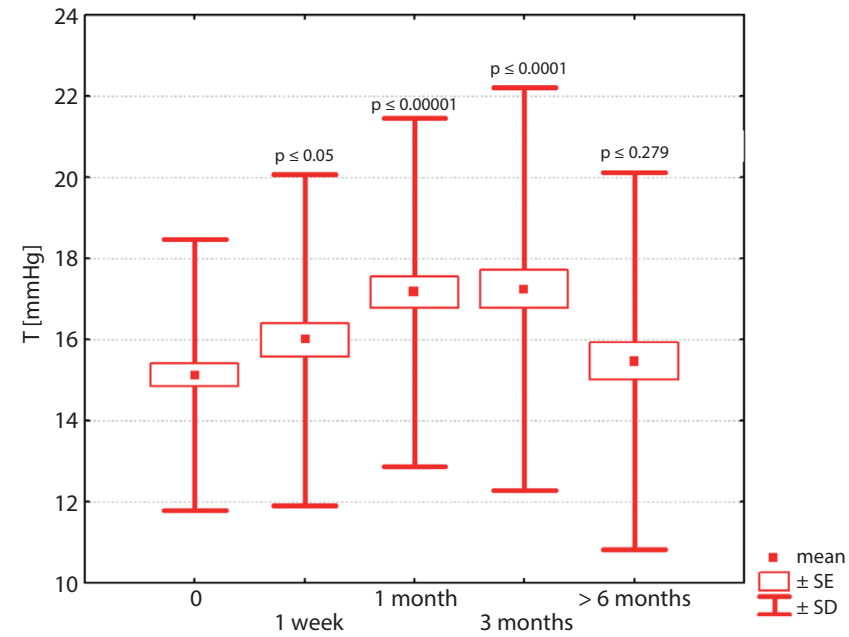

Fig. 4. Intraocular pressure (T, $\mathrm{mm} \mathrm{Hg}$ ) in the follow-ups in comparison to the initial intraocular pressure. SE - standard error; SD - standard deviation

initial and final IOP measurements in the observed group was not statistically significant either.

Trabeculectomies were necessary in two patients to lower their IOP to a safe level. Pharmacological treatment was sufficient in the other cases of increased IOP. Endophthalmitis was not observed in the study group.

\section{Discussion}

Due to the frequent ineffectiveness of laser treatment in DME patients, treatment with intravitreally triamcinolone injections was recently proposed. Crystalline triamcinolone in intravitreal injections turned out to be effective in limiting diabetic inflammatory reactions in the microcirculation. ${ }^{8}$ Machemer suggested using a depot form of steroids due to the intravitreal absorption time of 2-5 months. ${ }^{12,13}$ In the present study the decision was made to inject $20 \mathrm{mg}$ of triamcinolone acetonide to achieve an extended activity time, knowing that a dose of $4 \mathrm{mg}$ triamcinolone acetonide could be effective no longer than 3 months. ${ }^{14}$ In making this decision it was important that increases in intraocular pressure induced by triamcinolone acetonide are reported not to be markedly dependent on the dosage used. ${ }^{15}$ Furthermore, in research on rat retinas, the potential retinal toxicity of triamcinolone acetonide administered in high doses was not evident, in contrast to the effects of other steroids. ${ }^{16}$

Apart from a decrease in central retinal thickness, the patients in the current treatment group showed significant improvements in BCVA for distant and near vision after IVTA.

The improvement in distance BCVA was no longer statistically significant in the examined group after repeated injections. Due to recurrent DME, IVTA injections were repeated in 53 eyes twice, in 17 eyes three times, in 6 eyes 4 times, and in 1 eye 5 times. Repeated BCVA improve- ment was achieved in the treated eyes at most of the follow-up observation time points. Four patients had to undergo both a second IVTA and cataract extraction due to observed cataract progression.

After a 6-month observation period, 6 patients were diagnosed with DME of a mostly tractional character. In these patients only a minimal effect was observed after IVTA, so pars plana (PP) vitrectomies were performed, combined with phacoemulsification. In 17 other patients, IVTA was repeated after 6 months due to recurrent DME; 5 of these developed cataracts and the IVTA was combined with phacoemulsification. In 6 patients IVTA was repeated 4 times, and in 1 patient 5 times. In patients with recurrent DME after repeated IVTA, fluorescein angiography was carried out and compared with pretreatment images. In 5 such patients avascular zones, which were not covered by laser spots, were found in the periphery of the retina. This observation supports some suggestions from other authors that macular edema is caused by vascular endothelial growth factor (VEGF) from ischemia in the peripheral retina. ${ }^{17}$ The ETDRS guidelines do not recommend panretinal photocoagulation (PRP) for the treatment of DME; it is believed to provoke DME progression and an irreversible loss of visual acuity. However, it seems to the present authors that combining IVTA with PRP may make it possible to stabilize vision in some diabetic patients.

At the end of the present study's observation period, nine patients had been treated by pp vitrectomy and another three were prepared for it. The effects of the surgical treatment were not evaluated over an extended period of time and will be presented in a future publication. The authors' experience seems to suggest that the vitreoretinal interface changes in the course of diabetes and its treatment.

After IVTA and local and/or panretinal phocoagulation stabilization of the blood-retinal barrier can be achieved. Recurrent or remaining DME could be caused by traction of altered vitreo-retinal interface. Mechanical stress or stretch can also provoke leakage. There are no clear indications for treating DME by pp vitrectomy, and the decision to undertake it has to be made after careful observation.

The best balance for the patient should be ascertained at each examination.

Each diabetic patient needs a tailor-made decision. Although the recently completed Diabetic Retinopathy Clinical Research Network (DRCRnet) trial comparing photocoagulation and IVTA of 2 dosages ( $1 \mathrm{mg}$ or $4 \mathrm{mg}$ ) favored laser treatment in cases of changes in vision and central retinal thickening over time ${ }^{18}$, IVTA should still be considered in DME cases resistant to photocoagulation. IVTA may still be the only longer-acting treatment option for DME cases recurring shortly after anti-VEGF injections, which nowadays are commonly used in DME treatment. Even dexamethasone steroid implants (Ozur- 
dex), currently being introduced in DME treatment, may not have a longer duration than triamcinolone acetonide injections. ${ }^{19}$ Fluocinolone acetonide intravitreal implants (Iluvien) should be effective up to 36 months after intravitreal injection, but, like Ozurdex, will not be available in the near future for most diabetic patients due to its cost, which is not reimbursed by national health insurance in many countries. ${ }^{20}$

As there was no control group in the present study, it cannot conclusively be stated that the remission of diabetic edema was in each case the effect of the therapy; there is a chance that it might have occurred in the natural course of the disease. Moreover, the potential effects of glycemic levels or other systemic parameters that can influence the course of DME were not taken into account.

\section{Conclusions}

IVTA is useful in stabilizing the progression of DME, although its therapeutic effect can be time-limited.

\section{References}

1. Patz A, Schatz H, Berkow JW, Gittelsohn AM, Ticho U. Macular edema - an overlooked complication of diabetic retinopathy. Trans Am Acad Ophthalmol Otolaryngol. 1973;77(1):34-42.

2. Zimmet P, Alberti KG, Shaw J. Global and societal implications of the diabetes epidemic. Nature. 2014;14(6865):782-787.

3. Klein R, Moss SE, Klein BE, Gutierrez P, Mangione CM. The NEIVFQ-25 in people with long term type 1 diabetes mellitus: The Wisconsin Epidemiologic Study of Diabetic Retinopathy. Arch Ophthalmol. 2001;119(5):733-740.

4. Brown DM. Early Treatment Diabetic Retinopathy Study Research Group. Photocoagulation for diabetic macular edema: Early Treatment Diabetic Retinopathy Study report number 1. Arch Ophthalmol. 1985;103:1796-1806.

5. Jonas JB, Sofker A. Intraocular injection of crystalline cortisone as adjunctive treatment of diabetic macular edema. Am J Ophthalmol. 2001;132(3):425-457.
6. Jonas JB, Kreissig I, Sofker A, Degenring RF. Intravitreal injection of tiamcinolone for diffuse diabetic macular edema. Arch Ophthalmol. 2003;121(1):57-61.

7. Martidis A, Duker JS, Greenberg PB, et al. Intravitreal triamcinolone for refractory diabetic macular edema. Ophthalmology. 2001;109(5):920-927.

8. Avitable T, Longo A, Reibaldi A. Intravitreal triamcinolone compared with macular laser grid photocoagulation for the treatment of cystoid macular edema. Am J Ophthalmol. 2005;140(4):695-702.

9. Lam DS, Chan CK, Mohamed S, et al. A prospective randomized trial of different doses of intravitreal triamcinolone for diabetic macular oedema. Br J Ophthalmol. 2007;91(2):199-203.

10. Gillies MC, Sutter FK, Simpson JM, Larsson J, Ali H, Zhu M. Intravitreal triamcinolone for refractory diabetic macular edema: Two-year results of a double-masked, placebo-controlled, randomized clinical trial. Ophthalmology. 2006;113(9):1533-1538.

11. Sutter FK, Simpson JM, Gilies MC. Intravitreal triamcinolone for diabetic macular edema that persists after laser treatment: Threemonth efficacy and safety results of a prospective, randomized, double-masked, placebo-controlled clinical trial. Ophthalmology. 2004;111(11):2044-2049.

12. Schindler RH, Chandler DB, Thresher R, Machemer R. The clearance of intravitreal triamcinolone acetonide. Am J Ophthalmol. 1982;93:415-417.

13. Machemer R. Five cases in which a depot steroid (hydrocortisone acetate and methylprednisolone acetate) was injected into the eye. Retina. 1996;16:166-167.

14. Mason JO, Somaiva MD, Singh RJ. Intravitreal concentration of clearance of triamcinolone aceonide in nonvitrectomized human eyes. Retina. 2004;24(6):900-904.

15. Spandau UH, Derse M, Schmitz-Valckenberg P, Popoulis C, Jonas JB. Dosage dependency of intravitreal triamcinolone acetonide as treatment for diabetic macular edema. Br J Ophthalmol. 2005,89(8):999-1003.

16. Citirik M, Dilsiz N, Batman C, Zilelioglu O. Comparative toxicity of 4 commonly used intravitreally corticosteroids on rat retina. Can J Ophthalmol. 2009,44(3):e3-8.

17. Brown DM. Exploring the potential of combination therapies for DME. Retina Today 2009 (January Suppl.);8-10.

18. Diabetic Retinopathy Clinical Research Network. A randomized trial comparing intravitreal triamcinolone acetonide and focal/grid photocoagulation for diabetic macular edema. Ophthalmology. 2008;115:1447-1449.

19. Zucchiattil, Lattanzio R, Querques L, Del Turco C, Cascavilla ML, Bandello F. Intravitreal dexamethasone implant in patients with persistent diabetic macular edema. Ophthalmologica. 2012;228(2):117-122.

20. Sanford M. Fluocinolone acetonide intravitreal implant (lluvien) in diabetic macular oedema. Drugs. 2013;73(2):187-193. 